\title{
Valve Geometry and Flow Optimization through an Automated DOE Approach
}

\author{
Micaela Olivetti ${ }^{1, *}$, Federico Giulio Monterosso ${ }^{1, *}$, Gianluca Marinaro ${ }^{2} \mathbb{C}$, Emma Frosina ${ }^{2} \mathbb{D}$ \\ and Pietro Mazzei ${ }^{2}$ \\ 1 R\&D and Engineering Department, Omiq Srl, 20135 Milan, Italy \\ 2 Industrial Engineering Department, University of Naples Federico II, 80125 Naples, Italy; \\ gianluca.marinaro@unina.it (G.M.); emma.frosina@unina.it (E.F.); pie.mazzei@studenti.unina.it (P.M.) \\ * Correspondence: olivetti@omiq.it (M.O.); monterosso@omiq.it (F.G.M.)
}

Received: 4 December 2019; Accepted: 28 January 2020; Published: 30 January 2020

\begin{abstract}
The objective of this paper is to show how a completely virtual optimization approach is useful to design new geometries in order to improve the performance of industrial components, like valves. The standard approach for optimization of an industrial component, as a valve, is mainly performed with trials and errors and is based on the experience and knowledge of the engineer involved in the study. Unfortunately, this approach is time consuming and often not affordable for the industrial time-to-market. The introduction of computational fluid dynamic (CFD) tools significantly helped reducing time to market; on the other hand, the process to identify the best configuration still depends on the personal sensitivity of the engineer. Here a more general, faster and reliable approach is described, which uses a CFD code directly linked to an optimization tool. CAESES ${ }^{\circledR}$ associated with SimericsMP $+{ }^{\circledR}$ allows us to easily study many different geometrical variants and work out a design of experiments (DOE) sequence that gives evidence of the most impactful aspects of a design. Moreover, the result can be further optimized to obtain the best possible solution in terms of the constraints defined.
\end{abstract}

Keywords: optimization; valves; computational fluid dynamic (CFD); CAESES ${ }^{\circledR}$; SimericsMP+ ${ }^{\circledR}$

\section{Introduction}

It is well known that main and pilot stage valves, adopted in hydraulic circuits, have different performance requirements. Typically, main stage valves have high efficiency with adequate bandwidth and power, while pilot ones have rapid transient response and are stable and robust when facing external disturbances. When the power required by the pilot stage comes directly from the main line, pressure affects dynamic behavior and stability, making it difficult to tune the system to respond correctly to all pressure loads [1,2]. For this reason, different solutions are generally used to separate the two stages and make them as independent as possible.

The present study shows a technique to optimize a pilot operated distributor solenoid/hydraulic controlled valve. The presented modeling technique is based on the adoption of two tools, the optimization tool CAESES ${ }^{\circledR}$ (Friendship Systems AG, Postdam, Germany) and a commercial computational fluid dynamics (CFD) code: SimericsMP $+{ }^{\circledR}$ (Simerics Inc. ${ }^{\circledR}$, Bellevue, WA, USA).

This approach is faster than the one already presented by the authors [1,2] and can be applied to several geometries for the study of the components' internal fluid patterns.

Several examples of valve optimization are available in literature: some of them focused on the fluid dynamic, others on structural aspects [1-11].

Optimization tools and techniques are quite common in structural analysis, as they are used to reduce local stresses or to improve topology of mechanical parts. 
For example, Park et al. [12] proposed an approach based on a traditional structural optimization, which identifies the best combination of geometrical parameters to improve the product's performance and to save material. This paper presents a framework that performs the integration between commercial CAD-CAE software. This approach reduces the time for solving computation-intensive design optimization problems so that designers are free from monotonous repetitive tasks. The results show that the proposed method facilitates the structural optimization process and reduces the computing cost compared to other approaches.

Regarding the fluid dynamic aspect, the main problem is to identify how the fluid behaves inside the component. Some examples of fluid dynamic optimization can be found in literature [5-7].

Manring et al. $[7,8]$ modeled a spool-valve to study the flow forces acting on the valve spool. In other scientific papers, the same authors showed the experimental investigation carried out on hydraulic spool valves to measure the pressure transient force action on the valve's spool. The importance of optimizing fluid dynamic forces in modeling and testing approaches was demonstrated by these studies.

Zardin et al. [9] studied valves for mobile applications via a lumped parameter approach. They proposed an innovative design procedure to optimize valve design. The technique involves dedicated simulations to analyze the main critical issues regarding a cartridge valve. Models and simulations were used to define a methodology for designing a new valve. The optimized valve satisfies the requirements and adapts well to the necessities of operating at higher flow and pressure levels without compromising performances.

A useful tool to understand the flow behavior inside a component is three-dimensional computational fluid dynamics, a collection of different numerical techniques that allow to solve the Navier-Stokes equations.

Unfortunately, a main obstacle to implement optimization studies in fluid-dynamics analysis is, still today, computational cost. Furthermore, the setup of such projects typically requires three different tools to interact efficiently: a parametric geometry modeler (CAD), a computational fluid dynamics (CFD) solver and an optimization tool.

Tonomura et al. [13] showed a methodology for the optimization of a microdevice. Even if this component is not in the fluid power field, the approach used could be easily adopted in many research sectors. Authors studied a specific part inside the component using computational fluid dynamics (CFD). Then, a CFD-based optimization method was proposed for the design of plate-fin microdevices. With this approach, the optimal shape was designed almost automatically.

Corvaglia et al. [10] showed an interesting study on a load sensing proportional valve. The valve was modelled using two 3D CFD numerical approaches. The models were validated in terms of flow rate and pressure drop for different positions of the main spool by means of specific tests. This paper brought to evidence the reliability of the CFD models in evaluating the steady-state characteristics of valves with complex geometry.

Salvador et al. [11] adopted a computational fluid dynamics (CFD) approach to design hydraulic components such as valves by inexpensively providing insight into flow patterns, potential noise sources and cavitation. They demonstrated the relevance of the geometric characteristics on the performance. A modification of the geometry in the piston exit leads, for example, to different vortex structures and helps reduce vibrations and forces on the piston.

As mentioned before, Frosina et al. [1,2,8] already studied the valves' fluid-dynamics in order to analyze flow forces, pressures distribution and velocity behavior. All these studies were performed using 1D and 3D CFD modeling approaches depending on the application. Studies have demonstrated the accuracy of the developed methodologies and showed good agreement with experimental data. Geometric parameters were characterized and consequently modified systematically. The three-dimensional model's results, like velocity behavior and pressure distribution, allowed the authors of the study to optimize the valve geometry without losing any of the valve's performance. In 
this context, it would have been very advantageous to have access to an automated procedure that could drastically reduce the project duration.

For the project described in this article, just two tools were used: CAESES ${ }^{\circledR}$ (an optimization tool with integrated parametric geometry modelling capabilities) and SimericsMP+ ${ }^{\circledR}$, a commercial CFD solver. This approach greatly reduced the set-up effort and allowed for a leaner and more efficient project layout.

The objective of this work is to show how the shape of a valve ports can be automatically modified, without the use of an external CAD tool, and simulated to obtain the best performing geometry in just a few hours.

The design taken into consideration for the optimization is the geometry of a four-way hydro-piloted valve for industrial applications. In particular, the shape of two ports of the valve was optimized in order to obtain the highest possible mass flux at an imposed pressure drop.

The study began from a baseline geometry, tested with the CFD tool, from which the optimization started.

In the following paragraphs, the integration between the optimizer and the CFD tool as well as the results obtained will be described.

\section{Materials and Methods}

The DSP10 valve by Duplomatic MS S.p.A. (Parabiago-MI, Italy) was the object of the optimization study (Figure 1).

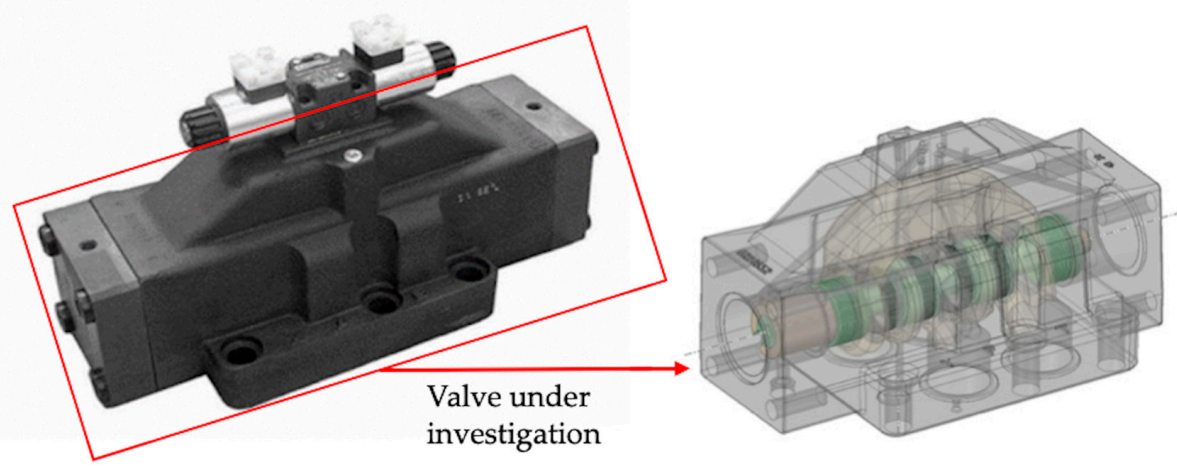

Figure 1. Valve under investigation.

It is worth noting that a good overall agreement between CFD studies conducted with SimericsMP $+{ }^{\circledR}$ on similar Duplomatic MS S.p.A. valves and experimental tests performed at the Industrial Engineering Department of the University of Naples, Federico II are reported in different publications (e.g., [1,8]).

For optimization purposes, the valve was simulated with fixed spool position so that only ports $\mathrm{P}$ and A (in blue in Figure 2) were connected through the spool port recesses (green in Figure 2).

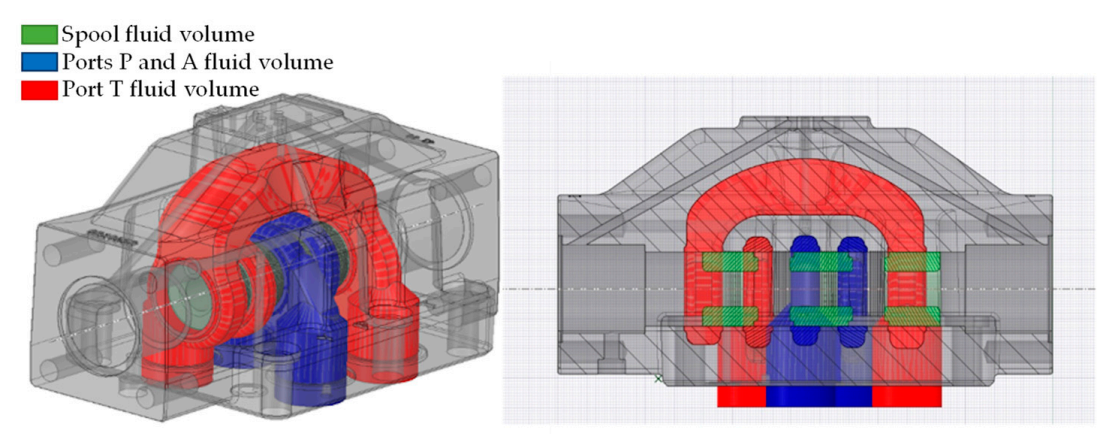

Figure 2. Ports A and P (blue) and spool caves (green). 
The volume wetted by the oil (Figure 3) was extracted with a CAD tool, and an STL file was exported to be used within the CFD code SimericsMP+ ${ }^{\circledR}$ (developed by Simerics Inc. ${ }^{\circledR}$, Bellevue, WA, USA)).

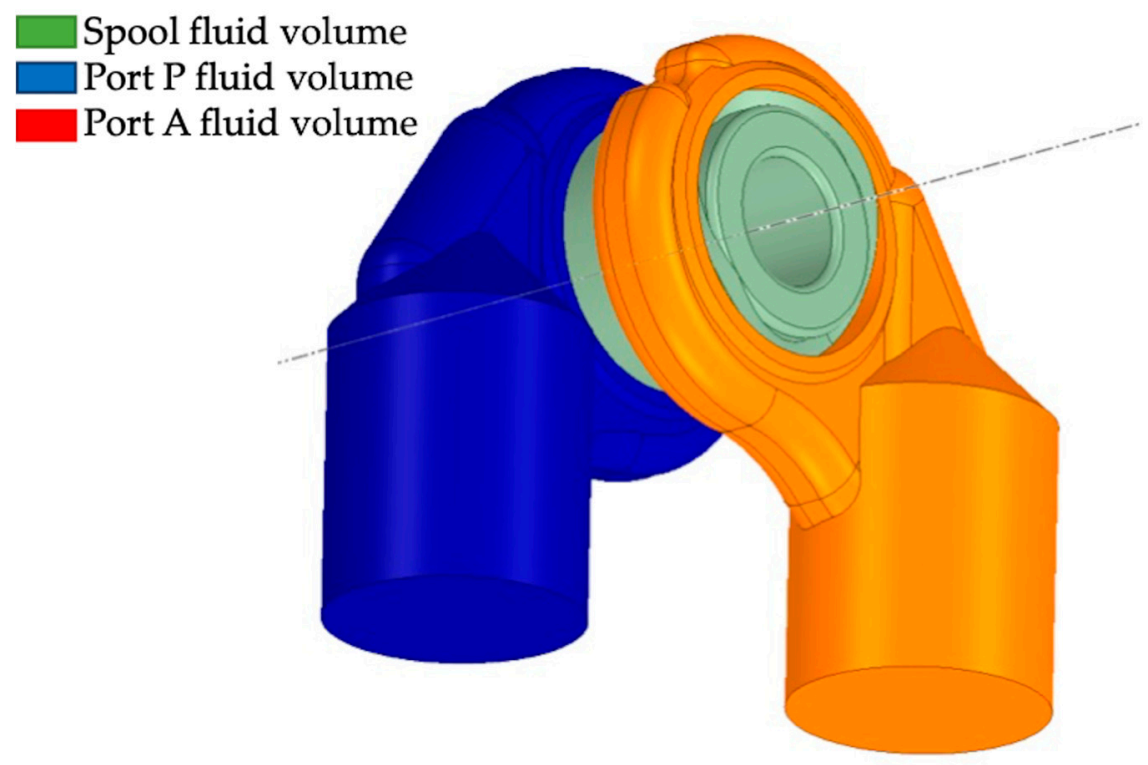

Figure 3. Fluid volumes of the valve.

In the performed study, the SimericsMP+ ${ }^{\circledR}$ tool was chosen as a general purpose CFD software that numerically solves the fundamental conservation equations of mass, momentum and energy as described below [14,15].

For the purposes of the study, some simplifications were considered, such as a stationary domain, a steady state flow and an isothermal flow. Given these approximations, some terms of the equations written below are disregarded by the solver during the run.

Mass conservation:

$$
\frac{\partial}{\partial t} \int_{\Omega(t)} \rho d \Omega+\int_{\sigma} \rho\left(v-v_{\sigma}\right) \cdot n d \sigma=0
$$

Momentum conservation:

$$
\frac{\partial}{\partial t} \int_{\Omega(t)} \rho v d \Omega+\int_{\sigma} \rho\left(\left(v-v_{\sigma}\right) \cdot n\right) v d \sigma=\int_{\sigma} \tilde{\tau} \cdot n d \sigma-\int_{\sigma} p n d \sigma+\int_{\Omega} f d \Omega
$$

Energy conservation:

$$
\frac{\vartheta}{\vartheta t}\left[\rho\left(u+\frac{v^{2}}{2}+g z\right)\right]+\nabla\left[\rho v\left(h+\frac{v^{2}}{2}+g z\right)\right]+\nabla Q-\nabla\left(T_{d} v\right)=0
$$

in which

- $\Omega(t)$ is the control volume,

- $\sigma$ is the control volume surface,

- $n$ is the surface normal pointed outwards,

- $\rho$ is the fluid density,

- $\quad p$ is the pressure,

- $f$ is the body force,

- $v$ is the fluid velocity,

- $v_{\sigma}$ is the surface motion velocity. 
$\widetilde{\tau}$, the shear stress tensor, is a function of the fluid viscosity $\mu$ and of the velocity gradient. For a Newtonian fluid, this is given by the following Equation (4),

$$
\tau_{i j}=\mu\left(\frac{\vartheta u_{i}}{\vartheta x_{j}}+\frac{\vartheta u_{j}}{\vartheta x_{i}}\right)-\frac{2}{3} \mu \frac{\vartheta u_{k}}{\vartheta x_{k}} \delta_{i j}
$$

where $u_{i}(i=1,2,3)$ is the velocity component and $\delta_{i j}$ is the Kronecker delta function.

The software implements mature turbulence models, such as the standard $k-\varepsilon$ model and Re-Normalization Group (RNG) $k-\varepsilon$ model [16]. These models have been available for more than a decade and are widely demonstrated to provide good engineering results. The standard $\mathrm{k}-\varepsilon$ model, used for the simulations presented in this paper is based on the following two equations:

$$
\begin{gathered}
\frac{\vartheta}{\vartheta t} \int_{\Omega(t)} \rho k d \Omega+\int_{\sigma} \rho\left(\left(v-v_{\sigma}\right) n\right) k d \sigma=\int_{\sigma}\left(\mu+\frac{\mu_{t}}{\sigma_{k}}\right)(\nabla k n) d \sigma+\int_{\Omega}\left(G_{t}-\rho i e\right) d \Omega \\
\frac{\vartheta}{\vartheta t} \int_{\Omega(t)} \rho i e d \Omega+\int_{\sigma} \rho\left(\left(v-v_{\sigma}\right) n\right) \varepsilon d \sigma \\
=\int_{\sigma}\left(\mu+\frac{\mu_{t}}{\sigma_{\varepsilon}}\right)(\nabla i e n) d \sigma+\int_{\Omega}\left(c_{1} G_{t} \frac{\varepsilon}{k}-c_{2} \rho \frac{\varepsilon^{2}}{k}\right) d \Omega
\end{gathered}
$$

with $c_{1}=1.44, c_{2}=1.92, \sigma_{k}=1, \sigma_{\varepsilon}=1.3$; where $\sigma_{k}$ e $\sigma_{\varepsilon}$ are the turbulent kinetic energy and the turbulent kinetic energy dissipation rate Prandtl numbers.

The turbulent kinetic energy, $k$, is defined as:

$$
k=\frac{1}{2}\left(v^{\prime} \cdot v^{\prime}\right)
$$

with $v^{\prime}$ being the turbulent fluctuation velocity, and the dissipation rate, $\varepsilon$, of the turbulent kinetic energy is defined as:

$$
\varepsilon=2 \frac{\mu}{\rho} \overline{\left(S_{i j}^{\prime} S_{i j}^{\prime}\right)}
$$

in which the strain tensor is:

$$
S_{i j}^{\prime}=\frac{1}{2}\left(\frac{\vartheta u_{i}^{\prime}}{\vartheta x_{j}}+\frac{\vartheta u_{j}^{\prime}}{\vartheta x_{i}}\right)
$$

with $u_{i}{ }^{\prime}(i=1,2,3)$ being components of $v^{\prime}$.

The turbulent viscosity $\mu_{t}$ is calculated by:

$$
\mu_{t}=\rho C_{\mu} \frac{k^{2}}{i e}
$$

with $C_{\mu}=0.09$.

The turbulent generation term $G_{t}$ can be expressed as a function of velocity and the shear stress tensor as:

$$
G_{t}=-\rho \overline{u^{\prime}{ }_{i} u^{\prime}} ; \frac{\vartheta u^{\prime}}{\vartheta x_{j}}
$$

where $\tau^{\prime}{ }_{i j}=\rho \overline{u^{\prime}{ }_{i} u_{j}^{\prime}}$ is the turbulent Reynolds stress, which can be modelled by the Boussinesq hypothesis:

$$
\tau^{\prime}{ }_{i j}=\mu_{t}\left(\frac{\vartheta u_{i}}{\vartheta x_{j}}+\frac{\vartheta u_{j}}{\vartheta x_{i}}\right)-\frac{2}{3}\left(\rho k+\frac{\vartheta u_{k}}{\vartheta x_{k}}\right) \delta_{i j}
$$

The valve fluid volume was meshed with the SimericsMP+ ${ }^{\circledR}$ grid generator (Figure 4). 


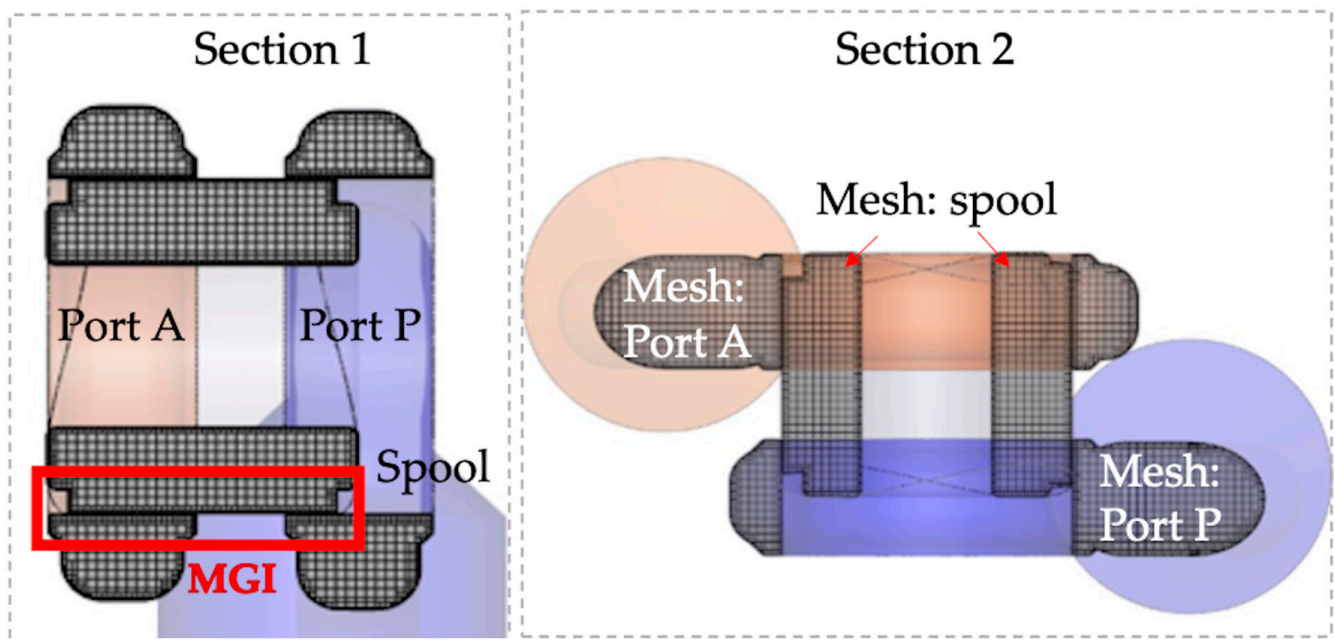

Figure 4. Grid seen from two different section planes.

SimericsMP+ ${ }^{\circledR}$ uses a body-fitted binary tree approach $[14,15]$

This type of grid is accurate and efficient because:

- The parent-child tree architecture allows for an expandable data structure with reduced memory storage;

- Binary refinement is optimal for transitioning between different length scales and resolutions within the model;

- Most cells are cubes, which is the optimum cell type in terms of orthogonality, aspect ratio and skewness, thereby reducing the influence of numerical errors and improving speed and accuracy;

- It can be automated, greatly reducing the set-up time.

In the configuration considered for the optimization, the spool is fixed in the position that allows the flux from Port P to Port A. The fluid volumes of the ports and the spool were meshed separately and were then connected via an implicit interface.

The SimericsMP $+{ }^{\circledR}$ mismatched grid interface (MGI, see Figure 5 ) is a very efficient implicit algorithm that identifies the overlap areas and matches them without interpolation. During the simulation process, the matching area is treated no differently than an internal face between two neighboring cells in the same grid domain.

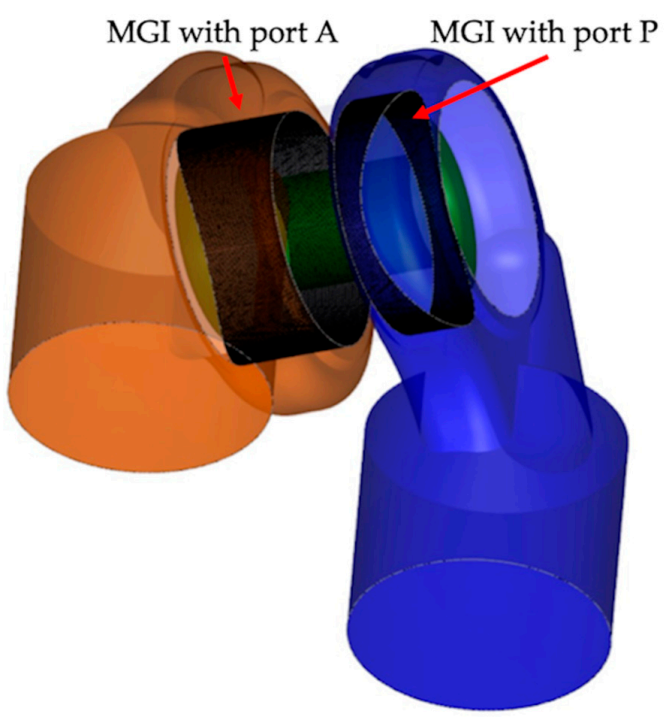

Figure 5. Mismatched grid interface (MGI) between the spool and both ports. 
Thanks to this approach, the solution becomes very robust, quick and accurate.

The DSP10 valve, the object of the study, was optimized at the most typical condition with a pressure difference of 5 bar.

The CFD model of the considered valve portion consists of 911,150 cells (Figure 4).

The following boundary conditions were applied (Figure 6):

- $\quad$ Fluid: oil at $45^{\circ} \mathrm{C}$ (constant)

- Oil kinematic viscosity: $4.42 \times 10^{-5}\left[\mathrm{~m}^{2} / \mathrm{s}\right]=44.2 \mathrm{cSt}$

- Oil density: $876\left[\mathrm{~kg} / \mathrm{m}^{3}\right]$

- Inlet, Port P: fixed static absolute pressure 50 bar

- Outlet, Port A: fixed static absolute pressure of 45 bar

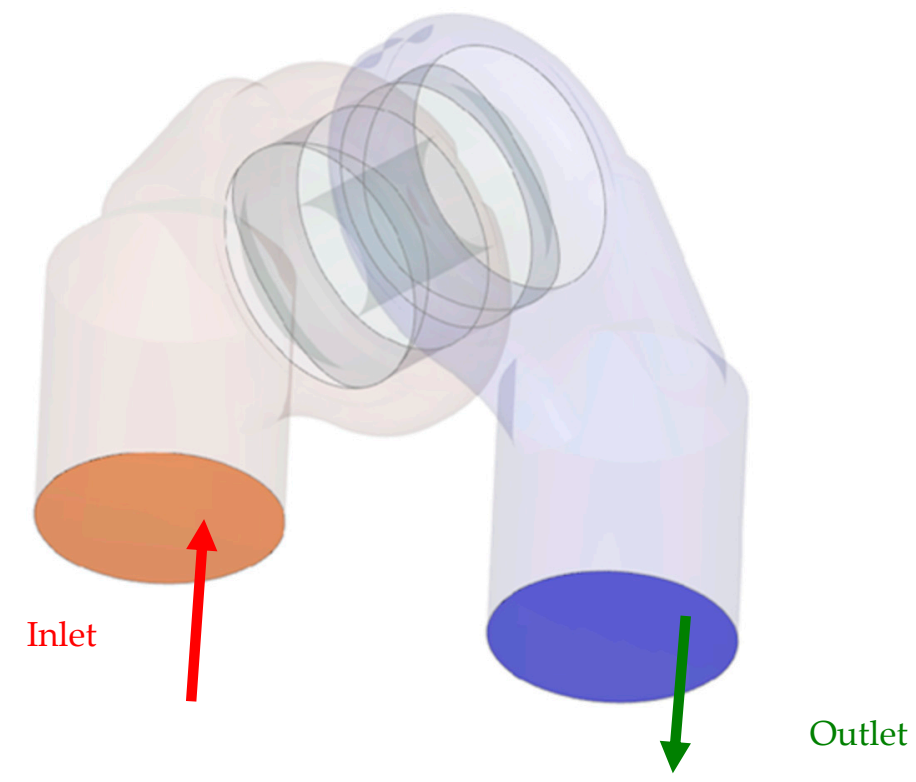

Figure 6. Boundary conditions on Port A and P.

A static analysis with turbulence was performed on the model. Run time for this analysis was 14 min on an 8 cores Intel Core i7, 3.10 GHz processor with $32 \mathrm{Mb}$ RAM.

In this configuration, a baseline CFD analysis was performed, to be used as reference during the optimization process.

As previously indicated, the optimization process was driven by CAESES ${ }^{\circledR}$.

CAESES ${ }^{\circledR}$ stands for "CAE System Empowering Simulation" and its ultimate goal is to design optimal flow-exposed products [17]. Starting from a baseline geometry, it is possible within CAESES ${ }^{\circledR}$ to modify the geometry, using different strategies and imposing constraints and parameters to obtain a set of geometries and boundary conditions that will be treated as a design of experiments (DOE) set.

The strategies used for the geometry modifications are:

- $\quad$ Fully parametric modeling: It allows the user to build the geometry from scratch in CAESES ${ }^{\circledR}$, using a proprietary "Meta Surface technology". This technology gives the possibility of modifying the built-in geometry in all possible ways (Figure 8).

- Partially parametric modeling: It lets the user import existing geometries and morph or deform these geometries. This means that the original geometry can be "distorted and modified" using a sort of surrounding grid, with control points that drive the geometry modifications (Figure 7). 


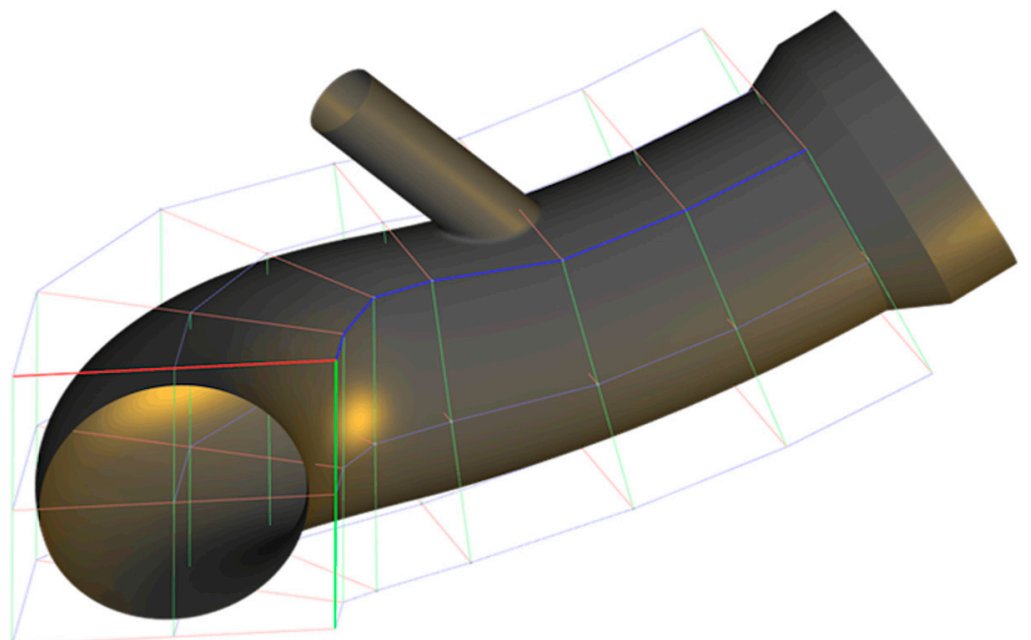

Figure 7. Partially parametric modelling.
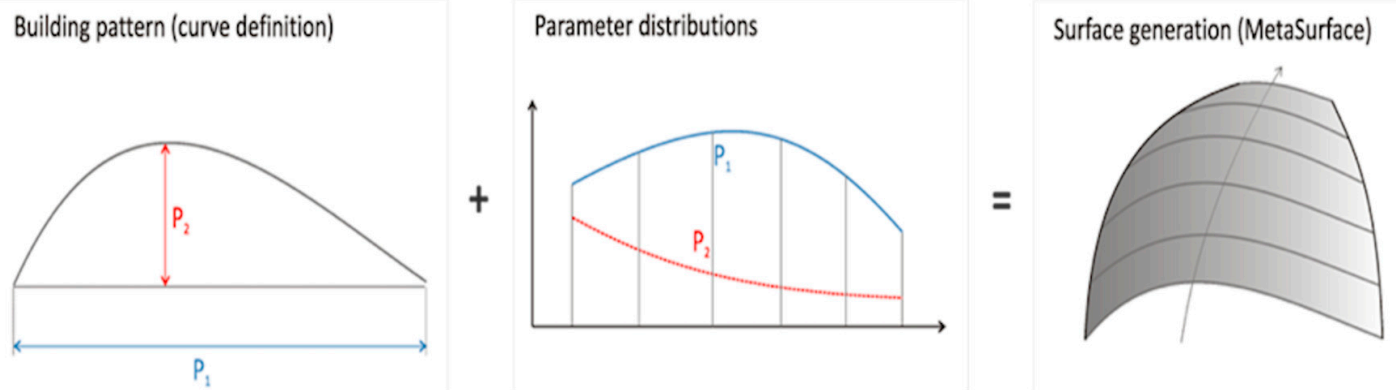

Figure 8. Fully parametric modelling.

Once the geometric strategy was chosen, $\mathrm{CAESES}^{\circledR}$ calculated all the possible shapes within the defined constraints and calculated a DOE sequence for the valid geometrical solutions.

The DOE sequence can also take into account variations of the boundary conditions, but the performed study was only based on geometrical modifications.

The ports of the valve, the object of the study, were modelled in CAESES ${ }^{\circledR}$ using the "fully parametric modelling" approach. The "partial parametric modeling" approach was used for other parts of the model (spool and other ports), although these parts have not been included in this phase of the project.

This means that the original geometry was rebuilt in CAESES ${ }^{\circledR}$ and different geometrical modifications of the valve ports $\mathrm{A}$ and $\mathrm{B}$ were taken into consideration.

CAESES ${ }^{\circledR}$ allows the user to select the geometry control parameters that are deemed relevant for the problem.

In the specific case, nine parameters for each port were identified:

- $\quad$ Box height (Figure 9)

- Box rotation

- Box shift

- Cap height

- Cap rotation

- Cylinder height

- Cylinder inclination

- Outer radius (Figure 10)

- Outer fillet 

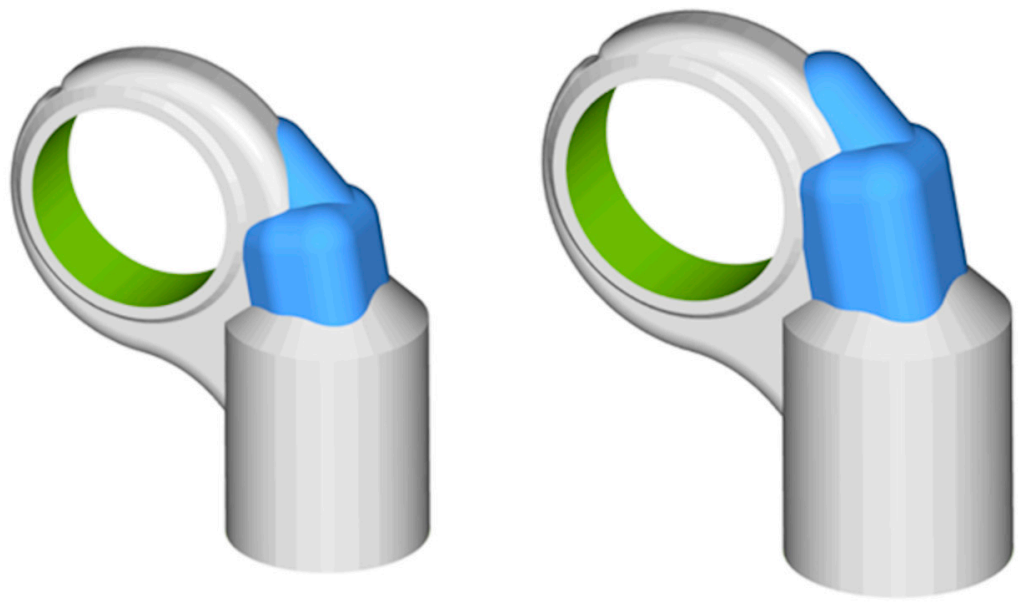

Figure 9. Box height variation. Left original, right max modification.
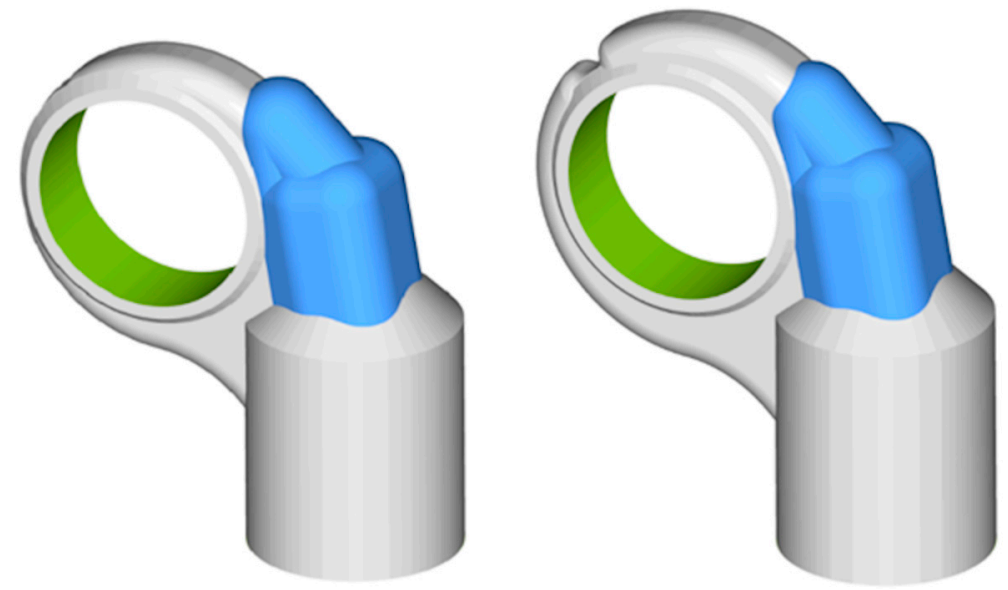

Figure 10. Outer radius variation. Left original, right max modification.

For example, in Figure 9, the box height modification is shown. In Figure 10 the outer radius variation is illustrated.

Not all the control parameters were used for the optimization: a DOE sequence generated with a Sobol algorithm identified four modifications for each port for a totally of eight design variables and 90 variants. In Table 1 these values are resumed.

Table 1. The eight design variables with their upper and lower values.

\begin{tabular}{cccc}
\hline Parameter & Lower Value & Upper Value & Initial Value \\
\hline Box shift for Port A & $-2.5[\mathrm{~mm}]$ & $-1.8[\mathrm{~mm}]$ & $-2[\mathrm{~mm}]$ \\
Box rotation for Port A & $5\left[\left[^{\circ}\right]\right.$ & $10\left[^{\circ}\right]$ & $10\left[{ }^{\circ}\right]$ \\
Outer circle radius for Port A & $1.45[\mathrm{~mm}]$ & $1.6[\mathrm{~mm}]$ & $1.5[\mathrm{~mm}]$ \\
Outer fillet radius for Port A & $10[\mathrm{~mm}]$ & $35[\mathrm{~mm}]$ & $30[\mathrm{~mm}]$ \\
Box shift for Port $\mathbf{P}$ & $-2.5[\mathrm{~mm}]$ & $-1[\mathrm{~mm}]$ & $-1.1[\mathrm{~mm}]$ \\
Box rotation for Port $\mathbf{P}$ & $5\left[^{\circ}\right]$ & $10\left[^{\circ}\right]$ & $9\left[^{\circ}\right]$ \\
Outer circle radius for Port $\mathbf{P}$ & $1.45[\mathrm{~mm}]$ & $1.6[\mathrm{~mm}]$ & $1.482[\mathrm{~mm}]$ \\
Outer fillet radius for Port $\mathbf{P}$ & $10[\mathrm{~mm}]$ & $35[\mathrm{~mm}]$ & $34.61[\mathrm{~mm}]$ \\
\hline
\end{tabular}

Two variables were monitored in CAESES $^{\circledR}$ : Port A and Port $\mathrm{P}$ volumes were monitored not to exceed predefined values.

The objective of the optimization was to maximize the mass flow rate of the valve at a fixed pressure drop. 
As the DOE sequence was defined, the CFD simulations for the 90 variants were performed with SimericsMP+ ${ }^{\circledR}$.

The great advantage of using CAESES ${ }^{\circledR}$ is that the code drives all the process automatically; this means that $\mathrm{CAESES}^{\circledR}$ generates the geometry that has to be tested on the base of the "design variables".

CAESES ${ }^{\circledR}$ creates the STL file that is used by SimericsMP+ ${ }^{\circledR}$ to generate the mesh. SimericsMP+ ${ }^{\circledR}$ is then run in batch and generates the new mesh, sets up the simulation and solves the case.

The results from SimericsMP $+{ }^{\circledR}$ are read, via a .txt file, from CAESES ${ }^{\circledR}$, that evaluates the obtained mass flux value.

Figure 11 illustrates the process scheme:

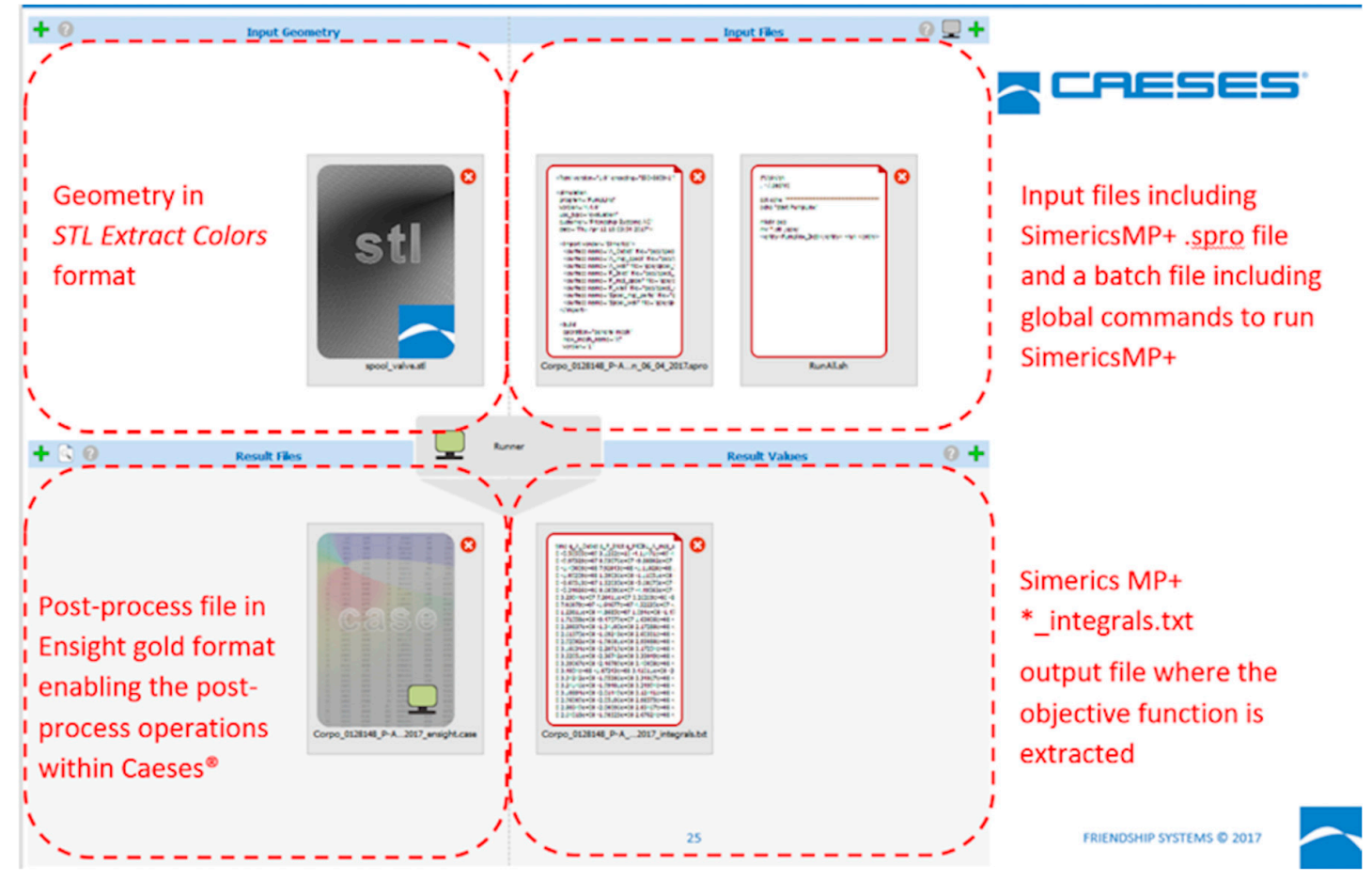

Figure 11. CAESES ${ }^{\circledR}$ automated process.

The CFD analyses were performed on all the 90 design variants.

Considering a mean simulation time of 15 min for SimericsMP+ ${ }^{\circledR}$ ' shared memory parallel solver on a single processor, eight cores workstation, the whole DOE sequence calculation took $22.5 \mathrm{~h}$; less than one day.

\section{Results}

\subsection{Baseline Computational Fluid Dynamics (CFD) Results}

Results obtained on the valve are shown in Figures 12-15. In particular, Figure 12 shows the pressure distribution on the walls of the fluid domain of the baseline geometry. It is clear that pressure was distributed according to the boundary conditions applied.

Other significative results are shown with two cross sectional views of the fluid domain: Figure 13 shows the pressure distribution, while Figure 14 is representative of the velocity behavior inside the domain.

Flux behavior inside the ports is also described with streamlines colored with the velocity magnitude in Figure 15.

The mass flux obtained with the baseline geometry $(13.47[\mathrm{~kg} / \mathrm{s}])$ was used as starting value for the optimization. 
The objective was therefore to find the maximum possible mass flux compatible with the prescribed constraints.

\& Simerics

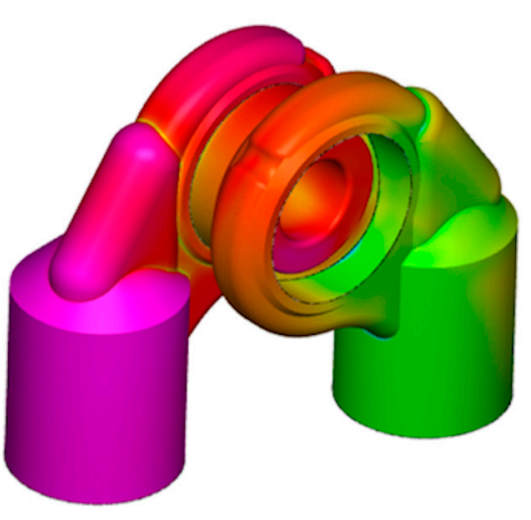

$L_{z}^{x}$

Figure 12. Pressure distribution on Port A and $\mathrm{P}$ walls, baseline geometry.

$$
\begin{gathered}
\text { Flbw: Pressure lbe } \\
50 \\
48.7904 \\
47.7508 \\
46.3712 \\
45.1615 \\
43.9519 \\
42.7423 \\
41.5327 \\
40.3231
\end{gathered}
$$

\& Simerics

$L_{z}^{x}$

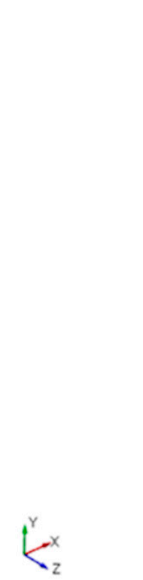

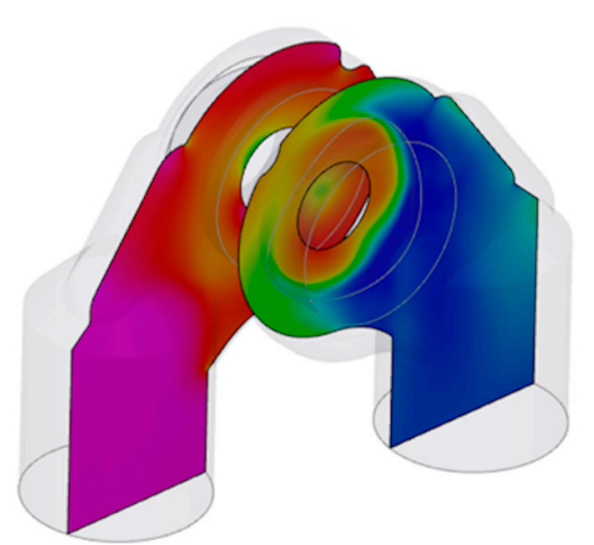

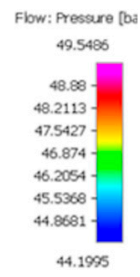

Figure 13. Pressure distribution on sections of Port A and Port $\mathrm{P}$, baseline geometry.

\& Simerics

Flow: Velocity Magritude $[\mathrm{m} / \mathrm{s}]$
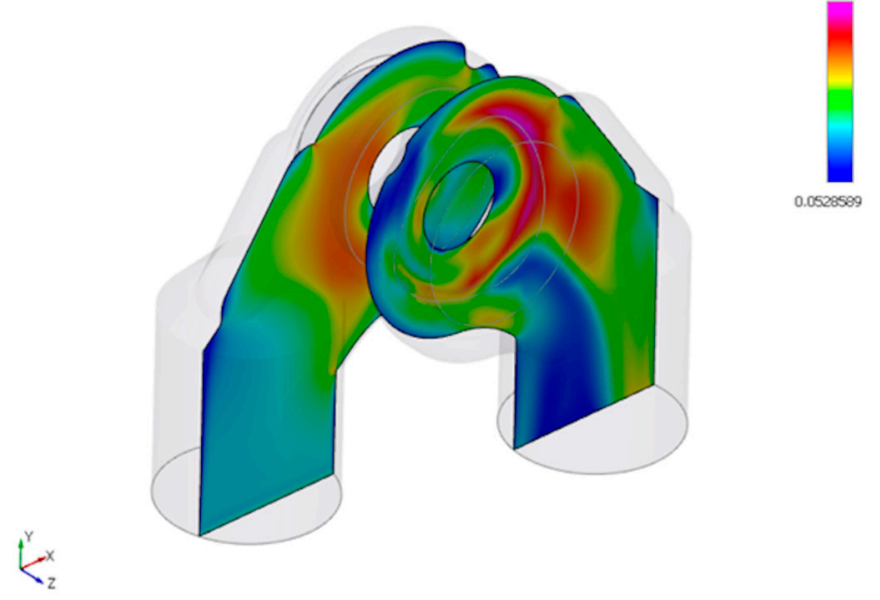

Figure 14. Velocity distribution on sections of Port A and Port P, baseline geometry. 


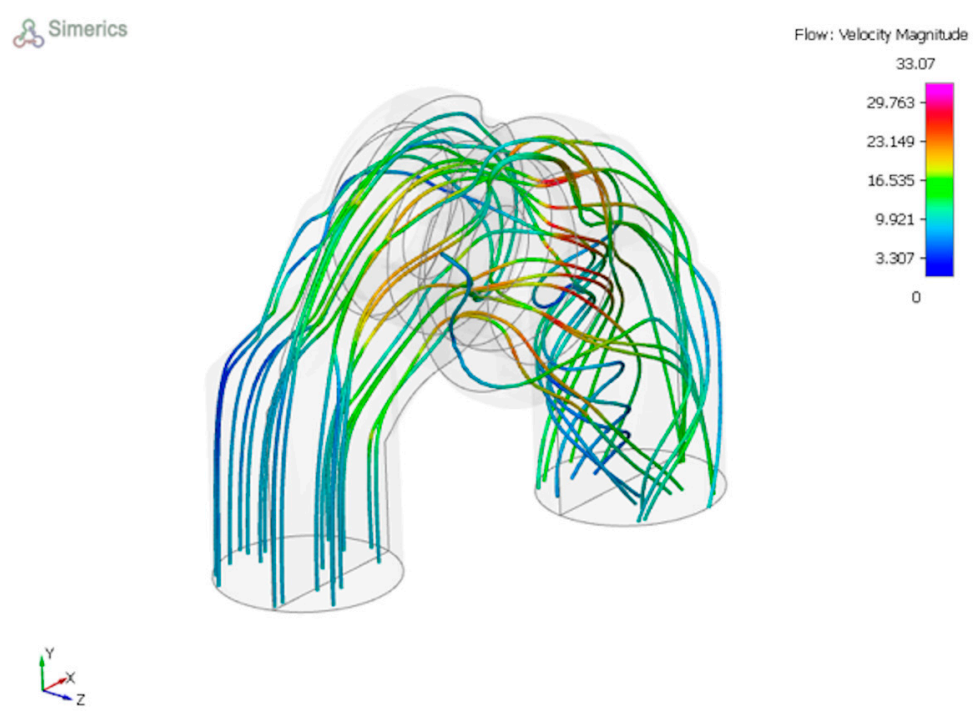

Figure 15. Streamlines in the valve, baseline geometry.

\subsection{Optimizaion Results}

At the end of the DOE sequence solution process, CAESES ${ }^{\circledR}$ provides a detailed table of all the data used in the calculations. For each simulated design, the corresponding geometric characteristics as well as calculations results are provided. In this specific project, as previously mentioned, 90 design variants were tested. A chart mapping 67 solutions versus the obtained flow rate can be visualized in Figure 16.

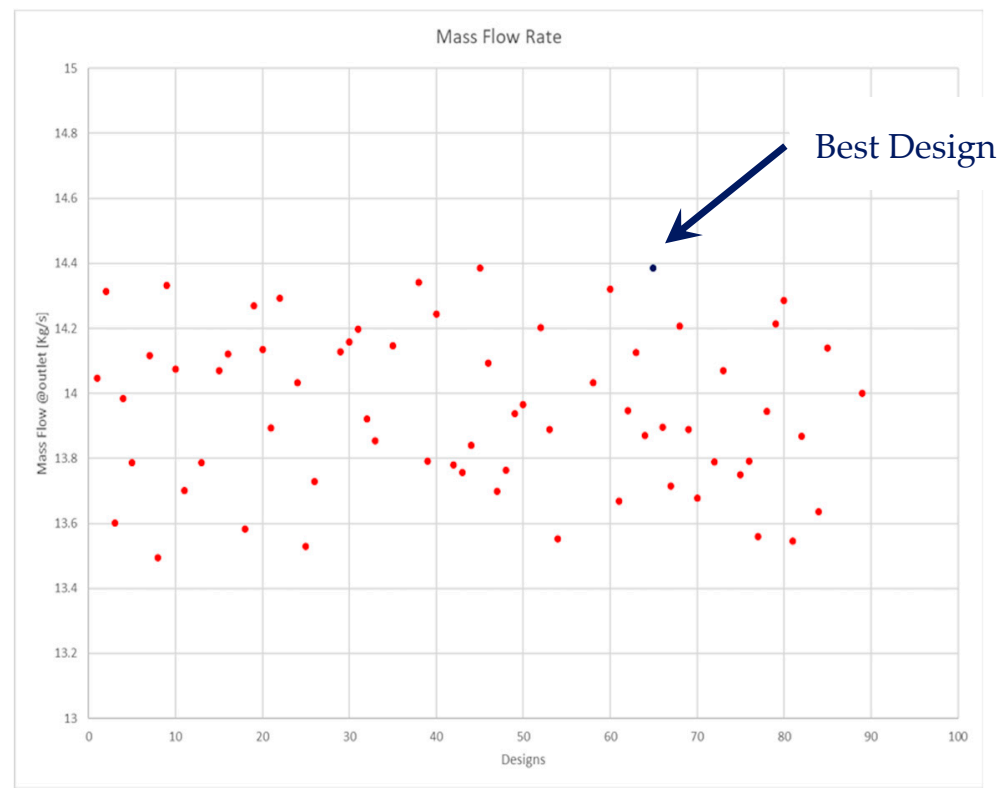

Figure 16. Design of experiments (DOE) results, in terms of mass flow at the outlet of the valve.

The remaining 23 solutions are not shown in the chart because of calculations failure. This means either that the simulation didn't end correctly or that the geometry could not be built with the prescribed parameters. All the 90 ports geometries had volumes within the limits requested, so that they could be contained in the original valve compartment. Ports volumes were monitored during the optimization process, even if they were not considered as a strict constraint.

The best mass flux obtained was $14.38[\mathrm{~kg} / \mathrm{s}]$ that, compared with the baseline result of $13.47[\mathrm{~kg} / \mathrm{s}]$, provided a $6.8 \%$ flow-rate increment. 
Table 2 sums up the geometric parameter values of the best solution, in comparison to the baseline geometry.

Table 2. Best design geometric values compared to the baseline geometry.

\begin{tabular}{ccc}
\hline Parameter & Baseline & Optimized \\
\hline Box height for Port A & $-2[\mathrm{~mm}]$ & $-1.871[\mathrm{~mm}]$ \\
Box rotation for Port A & $10\left[^{\circ}\right]$ & $7.617\left[\left[^{\circ}\right]\right.$ \\
Outer circle radius for Port A & $1.5[\mathrm{~mm}]$ & $1.592[\mathrm{~mm}]$ \\
Outer fillet radius for Port A & $30[\mathrm{~mm}]$ & $17.62[\mathrm{~mm}]$ \\
Box height for Port P & $-1.1[\mathrm{~mm}]$ & $-1.949[\mathrm{~mm}]$ \\
Box rotation for Port P & $9\left[^{\circ}\right]$ & $8.555\left[^{\circ}\right]$ \\
Outer circle radius for Port P & $1.482[\mathrm{~mm}]$ & $1.5847[\mathrm{~mm}]$ \\
Outer fillet radius for Port P & $34.61[\mathrm{~mm}]$ & $14.88\left[\mathrm{~mm}^{3}\right.$ \\
Volume Port A & $158,242\left[\mathrm{~mm}^{3}\right]$ & $175,369\left[\mathrm{~mm}^{3}\right]$ \\
Volume Port B & $158,967\left[\mathrm{~mm}^{3}\right]$ & $178,111\left[\mathrm{~mm}^{3}\right]$ \\
\hline
\end{tabular}

At the end of DOE sequence calculation, a parameter sensitivity analysis was performed to determine which parameter had the greatest influence on the mass flux.

Figure 17 shows the influence of the outer circle radius for Port A and P on the mass flux of the valve:

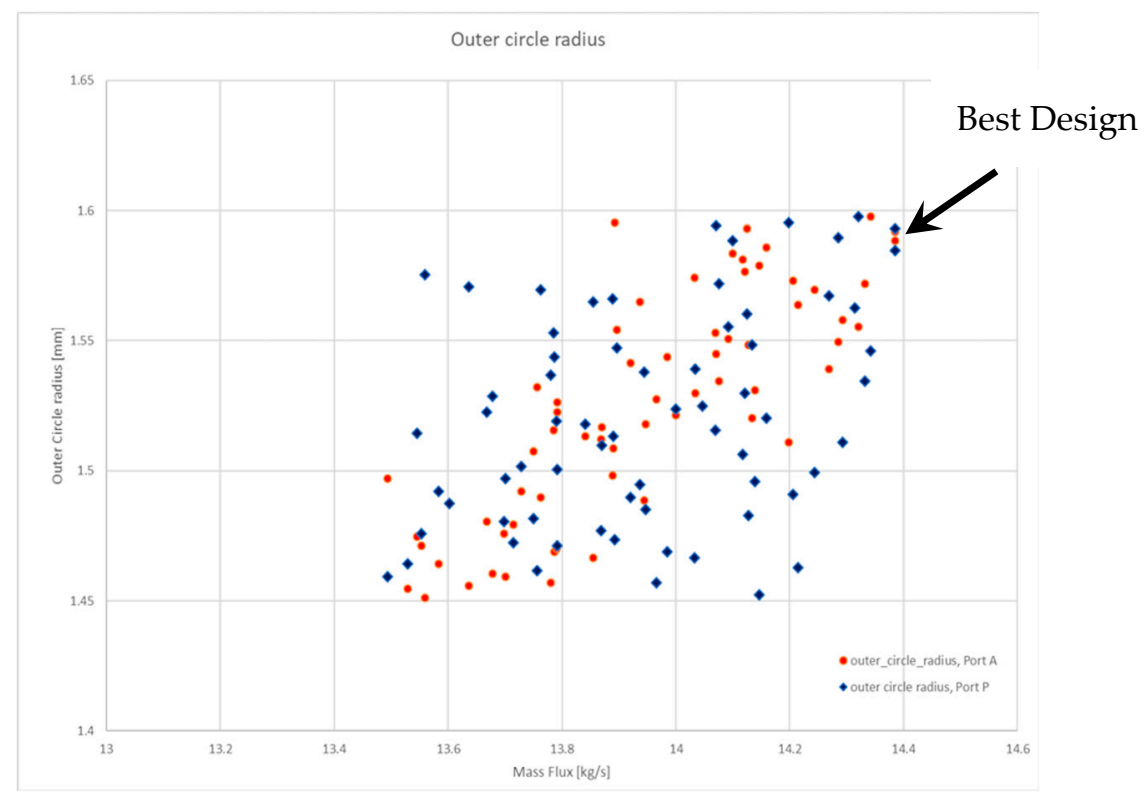

Figure 17. Outer circle radius impact on the optimization.

This parameter was the most effective in changing the mass flow value. In fact, small changes in the outer radius diameter provided a significant change in the mass flux: a $0.13 \mathrm{~mm}$ increment corresponded approximately a $1 \mathrm{~kg} / \mathrm{s}$ mass flux increase.

The process continued with a 2-level "Tsearch" optimization, starting from the best Sobol sequence design. "Tsearch" optimization is an optimization method based on the local tangent minimum and is aimed at improving the solution within the neighborhood of the selected design.

The T-Search method was originally proposed by Hilleary in 1966 [18]. It combines smaller steps and larger moves through the design space (a pattern search) and directly handles inequality constraints (see [19] for an elaboration). Mathematically speaking, it is a gradient-free method, but it comes up with probing moves not dissimilar to gradient directions. 
Results of the 2-level "Tsearch" optimization were very close to the best geometry obtained with the Sobol design of experiment sequence: they provided a further $2 \%$ increment in the mass flow rate of the valve.

Figure 18 shows the results obtained with the T-Search optimization.

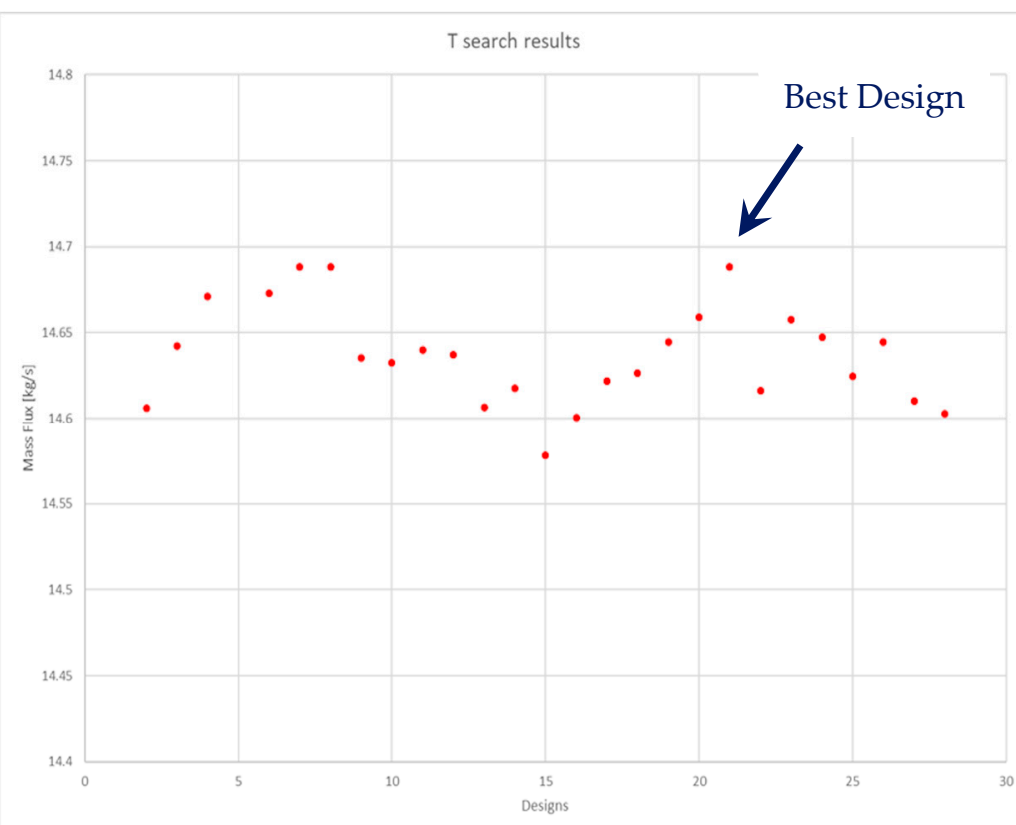

Figure 18. 2-level T-Search result.

In Table 3, best design results against baseline are compared.

Table 3. T-Search Optimization Results.

\begin{tabular}{ccc}
\hline Parameter & Baseline & Best Design \\
\hline Mass Flow rate $[\mathrm{kg} / \mathbf{s}]$ & 13.47 & 14.70 \\
Outer radius Port A $[\mathrm{mm}]$ & 1.5 & 1.595 \\
Outer radius Port $\mathbf{P}[\mathbf{m m}]$ & 1.5 & 1.595 \\
Volume Port A $\left[\mathbf{m}^{3}\right]$ & 0.000168 & 0.000176 \\
Volume Port $\mathbf{P}\left[\mathbf{m}^{3}\right]$ & 0.000170 & 0.000180 \\
\hline
\end{tabular}

\section{Optimized Geometry}

The final geometry obtained is illustrated in Figure 19. In Figure 20, a comparison between the baseline geometry and the optimized geometry is shown.

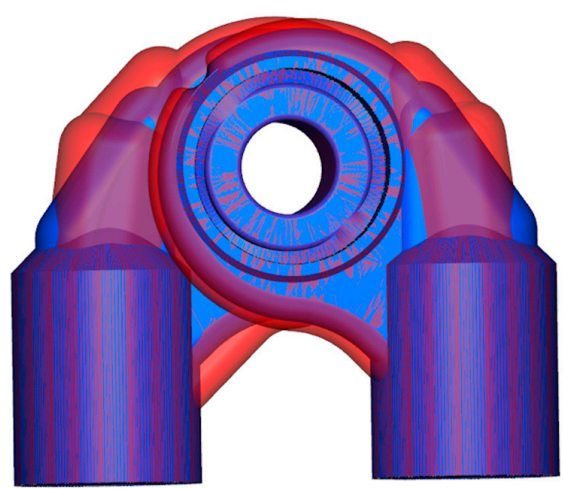

Figure 19. Final optimized geometry. 


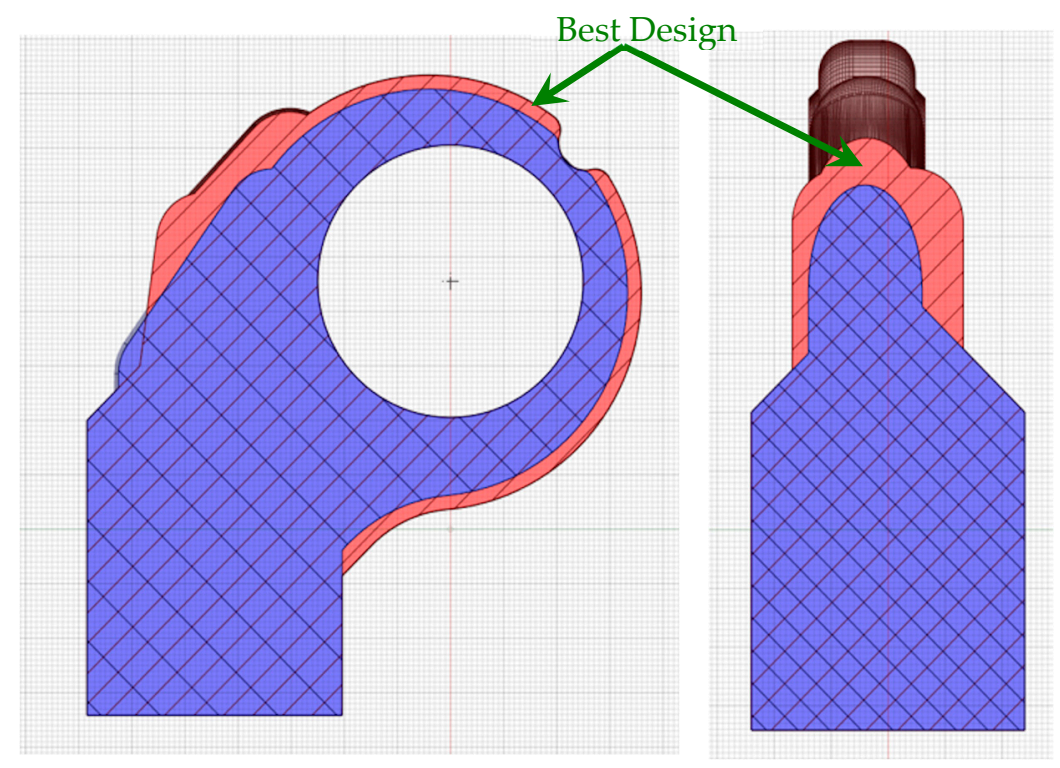

Figure 20. Geometry comparison.

As Figures 19 and 20 show, the main differences are on outer radius and box height, both in Port $\mathrm{P}$ and Port A.

\subsection{CFD Results on Optimized Geometry}

Results of CFD analysis are shown in Figures 21-24. The set-up of the analysis is the same described previously. In the images, the variables were set with the same scale as in the baseline simulation, for an easier comparison.

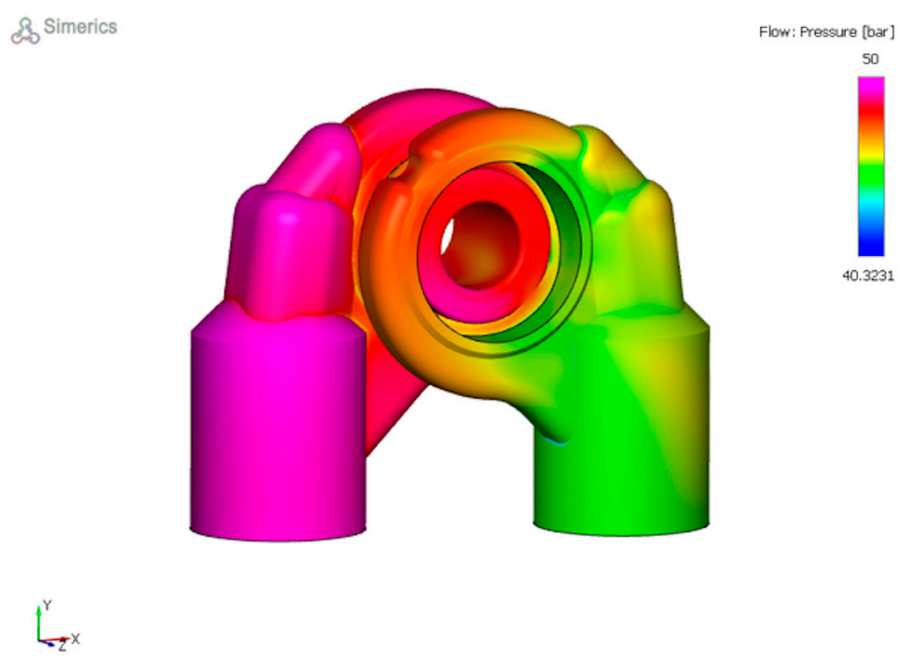

Figure 21. Pressure distribution on Port A and P walls, optimized geometry. 
$\&$ Simerics
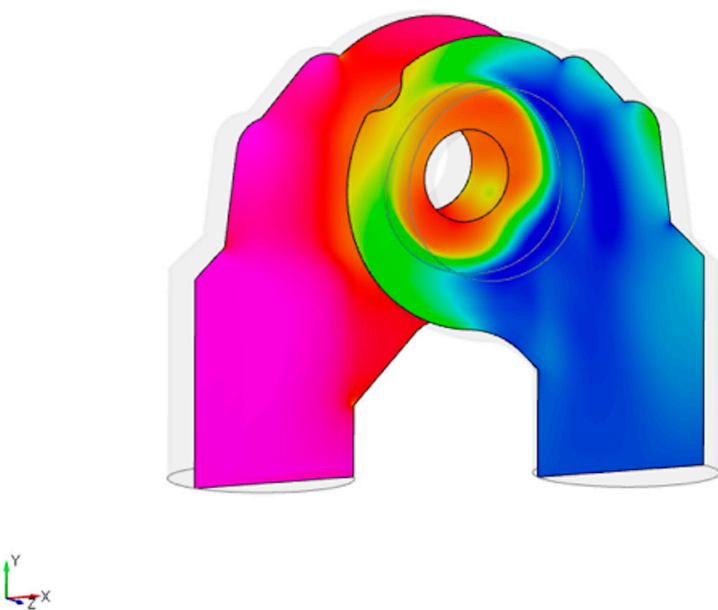

Figure 22. Pressure distribution on sections of Port A and Port P, optimized geometry.
Flow: Pressure [bar ]

49.548

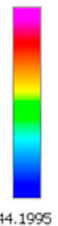

\& Simerics

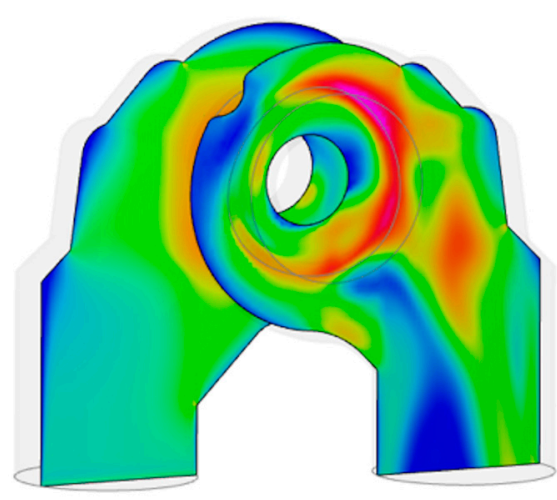

Flow: Velocity Magnitude

$$
\begin{array}{r}
26.1119 \\
20.321 \\
14.5301 \\
8.73919 \\
2.9483 \\
0.0526589
\end{array}
$$$$
29.0073
$$<smiles>[131In]</smiles>

Figure 23. Velocity distribution on sections of Port A and Port P, optimized geometry.

\& Simerics

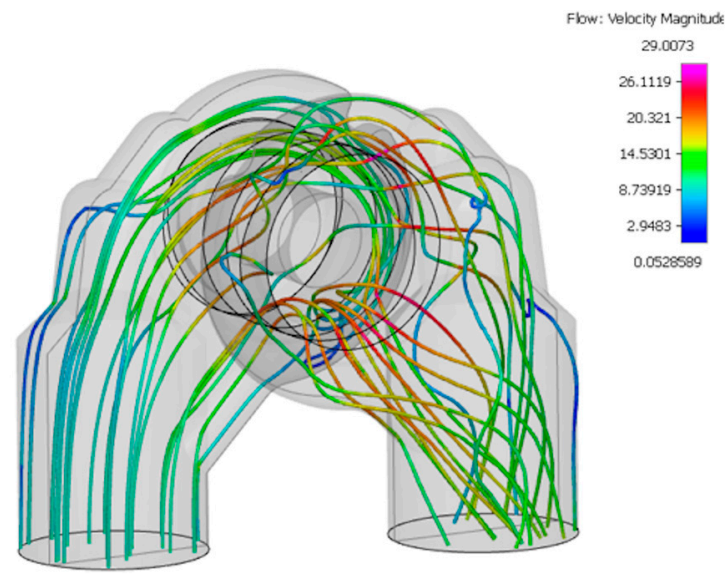

$L_{2}^{Y}$

Figure 24. Streamlines in the valve, optimized geometry. 


\section{Discussion}

This project shows how valve design can be virtualized and automated, provided that efficient and reliable software tools are available.

The advantage of this approach is the possibility of studying many different geometry variations, simply defining the parameters that are to be investigated. New geometries are automatically generated by CAESES ${ }^{\circledR}$ and then evaluated by Simerics MP+ ${ }^{\circledR}$. Answers can be obtained in very short time, also with different optimization techniques.

Optimization in this case was based on a two-step strategy. The first one, based on the Sobol design of experiment sequence, provides a geometry that let the valve increase the mass flux by about $7 \%$; the second, a T-Search method optimization, further adjusted the geometry to increase the mass flux by another $2 \%$. The overall process allowed for a $9 \%$ improvement in the mass flux. The ports' outer radius turned out to be the parameter that mostly influences the result.

Modifying this parameter allows an increase in the ports' volumes, and consequently a higher mass flux can be obtained.

However, larger ports' dimensions might be risky in terms of decelerating the fluid flowing in the valves. CFD results on the new geometry show that this is not the case, as the fluid velocities are not reduced significantly and are comparable with the baseline geometry velocities. The optimized geometry has also an advantage in terms of fluid behavior. Figure 25 shows a comparison of the velocity vectors distribution on the outlet ports for the baseline and optimized geometries: the vortex at the outlet port of the second geometry is significantly reduced.

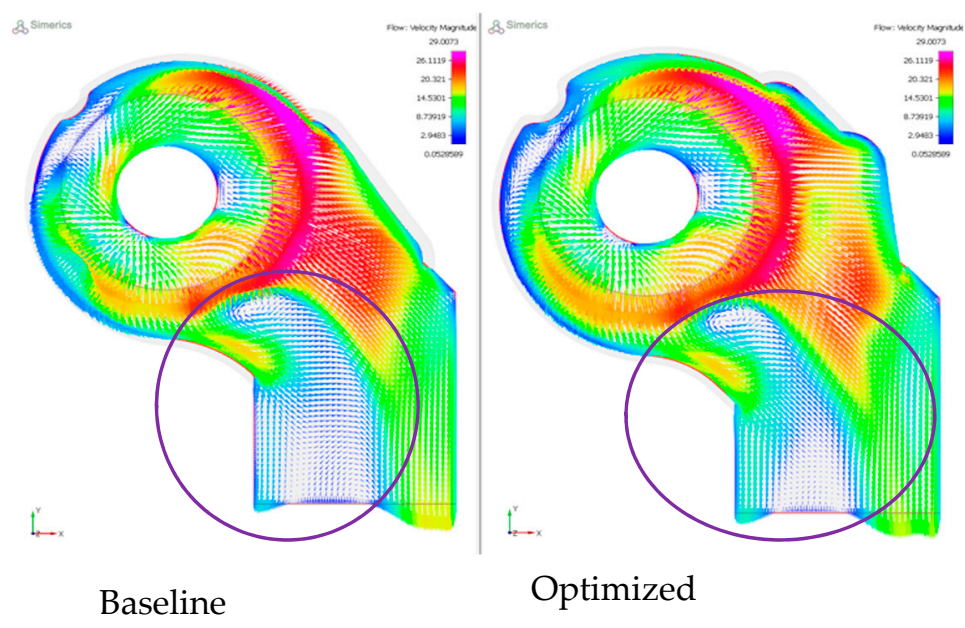

Figure 25. Comparison of the outlet vortex.

In Figure 26, another advantage of the larger outer radius is shown. Velocity distribution in the outer circumference is smoother in the new geometry and enters with an angle better aligned to the port exit section.

Experimental tests, carried out by Duplomatic MS S.p.A. at the Industrial Engineering Department at the University of Naples Federico II, show that the shape obtained by the optimization process are reliable, as expected from the conducted study.

It is worth noting that the authors conducted different studies on similar spool valves in order to achieve better performances. The Industrial Engineering Department proceeded to optimize the ports geometry with a traditional trial and error approach using laboratory testing and CFD. The results obtained in seven months are aligned to the results obtained with the optimization project performed with CAESES ${ }^{\circledR}$ and SimericsMP+ ${ }^{\circledR}$. 


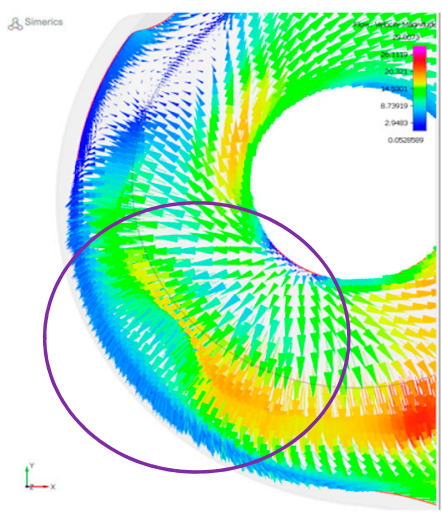

Baseline

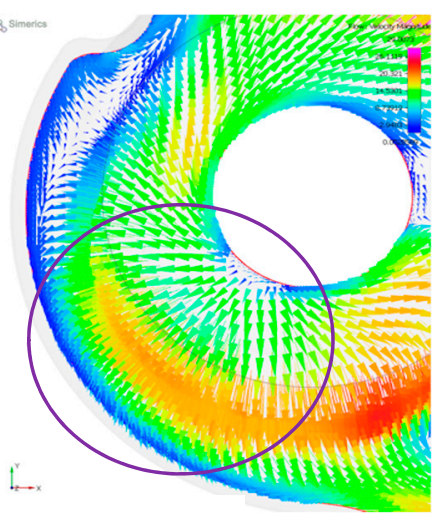

Optimized

Figure 26. Comparison of vortex in the outer circumference.

Although these two different approaches reached the same conclusions, two main points should be noted: First of all, the project timeline; seven months for the trial and error approach, one day for the automated approach.

Secondly, the methodology; the trial and error approach can be highly affected by engineer specific expertise while the automated approach is neutral in this respect and somehow free to investigate even apparently unreasonable solutions.

For both methods, the CFD simulation is an essential tool that helps understanding the behavior of the fluid inside the ports, either to find a new solution or to understand the reason for a solution being the optimal one.

\section{Conclusions}

A fast and reliable methodology to optimize the shape of the ports of a spool valve in order to obtain a higher mass flux was described. SimericsMP $+{ }^{\circledR}$ and CAESES ${ }^{\circledR}$ were used for this project.

Through these tools, an optimized geometry was automatically identified in a very short time. The advantage of the approach is that no parametric CAD tool is needed as CAESES ${ }^{\circledR}$ directly handles the automated process, including geometric modifications, simulations set up and run.

Moreover, a fast and reliable CFD simulation software, as Simerics $\mathrm{MP}+{ }^{\circledR}$, is necessary, as it accelerates the process to obtain the best geometry.

The conducted study also gave evidence of the fact that an optimizer is useful to identify the parameters that mostly influence the objective. Meanwhile, coupled with an efficient CFD solver, it allows investigation of the physics of the problem and determination of the sensitivity of the parameters.

Author Contributions: Conceptualization, M.O.; data curation, G.M. and P.M.; formal analysis, G.M. and P.M.; methodology, M.O. and E.F.; project administration, M.O. and F.G.M.; resources, G.M.; supervision, F.G.M.; Writing-original draft, M.O.; Writing-review \& editing, M.O. All authors have read and agreed to the published version of the manuscript.

Funding: This research was developed as part of a PhD program supported by the Italian Government and the MIUR (Ministry of Education, Universities and Research).

Acknowledgments: We would like to thank Ceyhan Erdem e Mike Saroch at Friendship Systems AG for providing outstanding technical support on this project.

Conflicts of Interest: The authors declare no conflict of interest. 


\section{Abbreviations/Nomenclature}

$\begin{array}{ll}\text { CAD } & \text { Computer Aided Design } \\ \text { CFD } & \text { Computational Fluid Dynamics } \\ \text { DOE } & \text { Design of Experiments } \\ \text { MGI } & \text { Mismatched Grid Interface } \\ \text { STL } & \text { Stereolithography } \\ \text { RNG } & \text { Re-Normalization Group }\end{array}$

\section{References}

1. Frosina, E.; Buono, D.; Senatore, A.; Stelson, K.A. A Mathematical Model to Analyze the Torque Caused by Fluid-Solid Interaction on a Hydraulic Valve. J. Fluids Eng. 2016, 138, 061103. [CrossRef]

2. Frosina, E.; Buono, D.; Senatore, A.; Stelson, K.A. A modeling approach to study the fluid dynamic forces acting on the spool of a flow control valve. J. Fluids Eng 2016, 139, 011103-011115. [CrossRef]

3. Ivantysynova, M.; Ivatysyn, J. Hydrostatic Pumps and Motors'; Vogel Buchverlag: Würzburg, Germany, 2001.

4. Fitch, E.C.; Homg, I.T. Hydraulic Component Design and Selection'; Bardyne Inc.: Stillwater, OK, USA, 2004.

5. Akers, A.; Gassman, M.; Smith, R. Hydraulic Power System Analysis'; CRC Press: Boca Raton, FL, USA, 2006.

6. Senatore, A.; Buono, D.; Frosina, E.; Pavanetto, M.; Costin, I.I.; Olivetti, M. Improving the control performance of a Proportional spool valve, using a 3D CFD modeling. In Proceedings of the IMECE04 2014 ASME International Mechanical Engineering Congress and Exposition, Montreal, Canada, 14-20 November 2014.

7. Manring, N.D. Modeling Spool-Valve Flow Force. In Proceedings of the ASME 2004 International Mechanical Engineering Congress and Exposition, Anaheim, CA, USA, 13-19 November 2004; pp. 23-29.

8. Manring, N.D.; Zhang, S. Pressure Transient Flow Forces for Hydraulic Spool Valves. J. Dyn. Sys. Meas. Control. 2011, 134, 034501. [CrossRef]

9. Zardin, B.; Borghi, M.; Cillo, G.; Rinaldini, C.A.; Mattarelli, E. Design Of Two-Stage On/Off Cartridge Valves For Mobile Applications. Energy Procedia 2017, 126, 1123-1130. [CrossRef]

10. Corvaglia, A.; Altare, G.; Finesso, R.; Rundo, M. Computational fluid dynamics modelling of a load sensing proportional valve. Proceeding of the ASME-JSME-KSME 2019 8th Joint Fluids Engineering Conference, San Francisco, CA, USA, 28 July-1 August 2019.

11. Plau-Salvador, G.; Gonzalez-Altozano, P.; Arviza-Valverde, J. Three-dimensional Modeling and Geometrical Influence on the Hydraulic Performance of a Control Valve. ASME J. Fluids Eng. 2008, 130, 0111021-0111029. [CrossRef]

12. Park, H.-S.; Dang, X.-P. Structural optimization based on CAD-CAE integration and metamodeling techniques. Comput. -Aided Des. 2010, 42, 889-902. [CrossRef]

13. Tonomura, O.; Tanaka, S.; Noda, M.; Kano, M.; Hasebe, S.; Hashimoto, I. CFD-based optimal design of manifold in plate-fin microdevices. Chem. Eng. J. 2004, 101, 397-402. [CrossRef]

14. SimericsMP+ User Manual. Available online: https://www.simerics.com/simerics-valve/ (accessed on 29 January 2020).

15. Ding, H.; Visser, F.C.; Jiang, Y.; Furmanczyk, M. Demonstration and Validation of a 3D CFD Simulation Tool Predicting Pump Performance and Cavitation for Industrial Applications. J. Fluids Eng. 2011, 133, 011101. [CrossRef]

16. Launder, B.E.; Spalding, D.B. The numerical computation of turbulent flows. Comput. Methods Appl. Mech. and Eng. 1974, 3, 269-289. [CrossRef]

17. CAESES ${ }^{\circledR}$ User Manual. Available online: https://www.caeses.com/products/caeses/ (accessed on 29 January 2020).

18. Hilleary, R.R. The Tangent Search Method of Constrained Minimization; Naval Postgraduate School: Monterey, CA, USA, 1966.

19. Birk, L.; Harries, S. OPTIMISTIC-Optimization in Marine Design; Mensch \& Buch Verlag: Berlin, Germany, 2003. 